\title{
WhatsApp as an ICT Tool in Higher Education- a Survey during COVID pandemic in the state of Goa.
}

\author{
Nisha Sawant ${ }^{1}$, Nilaxi Chari ${ }^{2}$ \\ ${ }^{1,2}$ Department of Computer Applications and IT, SPES'S Goa Multi-Faculty College, \\ Dharbandora, Goa
}

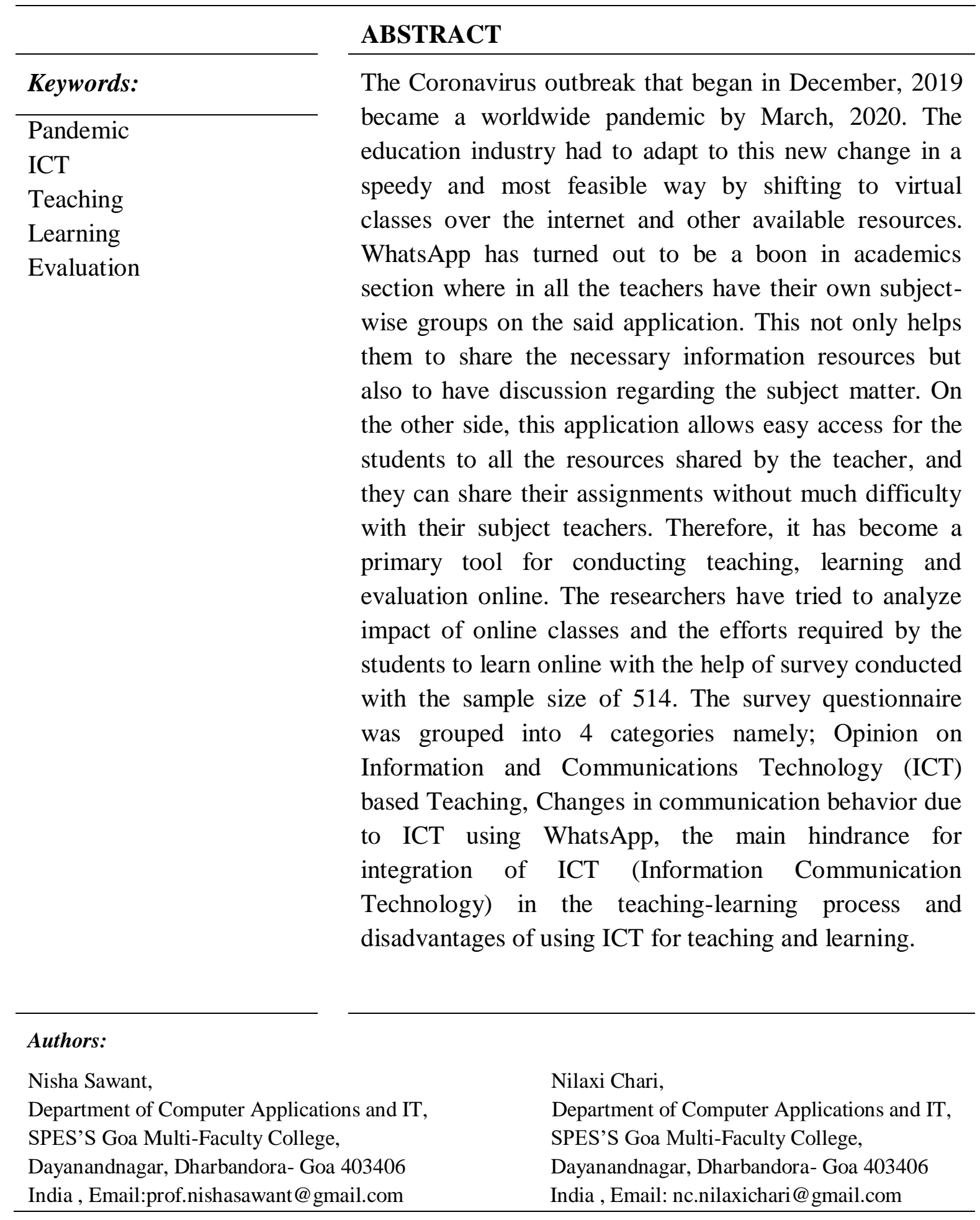




\section{INTRODUCTION}

Coronavirus outbreak across the World began in December 2019. It spread to the entire World very rapidly causing several cases of infections and deaths. On $15^{\text {th }}$ March 2020, the Government of Goa decided to close all the schools and colleges for students with immediate effect to contain the rapid spread of this virus. On $22^{\text {nd }}$ March 2020, Honorable Prime Minister, Shri Narendra Modi declared the first lockdown which prohibited movement of all persons except for essential needs. This lockdown kept on extending for months together and the result was that the students could not continue their learning journey.

Taking appropriate measures, guidelines and Standard Operating Procedures (SOPs) were laid down to begin teaching-learning process through digital platforms. Many schools and colleges started taking lectures on platforms like Google meet, Zoom (it was later discontinued owing to the privacy policy), Webex, etc. This was a paradigm shift for the entire Education Industry- the teachers, students, parents, and all other stakeholders.

There were many hiccups in the process such as issues related to internet connectivity, availability of the devices required (laptops, smartphones and tablets, etc.). In addition to this, teachers, students and their parents had to spend time training themselves to adapt to the online education requirements successfully. The online platform for teaching-learning eliminated the need of students to be physically present for classes. Many students started to exploit the online learning process by simply showing their virtual presence without being actually present for the class. It was very difficult to get a feedback from the students about their understanding of the subjects being taught online. And, few students who genuinely wanted to study were not able to attend the classes online due to network issues or because they could not afford to buy the resources needed for online learning. This situation motivated us to study the impact of WhatsApp as an ICT tool in Higher Education in the state of Goa.

Through various statements in the survey, the response of students for using WhatsApp as an educational tool of ICT are touched upon for self-retrospection of the students as well as a deep analysis by the surveyor of the overall responses.

\subsection{Terminology}

ICT (Information and Communication Technology) refers to technologies that provide access to information through telecommunications. It includes the hardware as well as software components.

WhatsApp Messenger, or WhatsApp, is an American freeware, cross-platform centralized messaging and voice-over-IP service owned by Facebook, Inc. It allows users to send text messages and voice messages, make voice and video calls, and share images, documents, user locations, and other content. Most of the youth use WhatsApp, because of which it is 
also used by the education system to communicate / share information with students. It has turned out to be a reliable and efficient software that helps in the teaching-learning process.

\subsection{Aims - hypothesis}

- To measure the effectiveness of WhatsApp as a tool for ICT in Higher Education.

- To understand the opinion of the students' and to analyze the changes in communication behavior due to ICT using WhatsApp.

- To analyze the various factors that affect optimum implementation of WhatsApp as an ICT Tool in the Higher Education.

- To analyze the other side of the implementation of WhatsApp as an ICT tool to understand the disadvantages of using ICT for teaching and learning.

\section{RESEARCH METHODOLOGY}

The research is based on mixed method with the combination of quantitative and qualitative approaches. Study is a blend of qualitative and quantitative data that is collected from the students of college sections and higher secondary schools in various talukas of Goa with the sample size of 511. This study also has used qualitative approach as the research is based upon the insights gained by interviewing the teaching faculty of few colleges about the behavior of the students online.

The study is based on the responses collected by the students with age group of 18 to 21 year from the State of Goa. The sample population is of size 514. The questionnaire for the survey is grouped into four categories - 1. Opinion on Information and Communication Technology (ICT) based teaching, 2. Changes in communication behavior due to ICT using WhatsApp, 3. Major challenges for integration of ICT in teaching-learning process and, 4. Disadvantages of using WhatsApp as an ICT tool.

The majority of respondents are from the college section. Maximum respondents are from rural areas where network connectivity is a major issue. Since, the respondents are young, they have personal mobile devices which so far were being used only for entertainment. Until the outbreak of pandemic, the students were used to a pattern of learning in classrooms with teachers and peers in a formal set-up. Through this study the researchers study the impact of the sudden change in the teaching-learning pattern from offline to online. The study aims to measure the impact of using WhatsApp as an ICT tool in Higher Education in the pandemic times. Students are used to a pattern of learning in classrooms with teachers and peers in a formal set-up.

\section{DATA ANALYSIS}

The students responded to a multiple-choice grid where various statements were provided with five different choices (only one of these could be selected for each statement). The 
choices for all the statements were Strongly Agree, Agree, Neutral, Disagree and Strongly Disagree. The statements were grouped into four broad categories listed below:

\subsection{Opinion on Information and Communications Technology (ICT) based Teaching:}

Under this criterion, seven statements related to the opinion of the students were given to the students for analyzing ICT based learning. The objective here was to understand how ICT helps in making communication better and enhance the teaching-learning experience for the students.

From the below analysis it is seen that the majority of students feel that it is necessary to incorporate ICT in Higher Education for faster and easier communication. Students agree that it has a huge positive impact on our daily life and improves the standards of education. In this pandemic time, ICT has served as a good replacement for the daily face-to-face classroom teaching and kept the enthusiasm and morale of students in the trying times. ICT also serves as a good means of interpersonal communication among students and teachers with reference to educational requirements. Majority of students believe that ICT can counter the shortcoming in traditional learning.

From the below graph, we can clearly see that less than 5\% students have responded in the negative saying that ICT is not effective for teaching-learning in Higher Education.

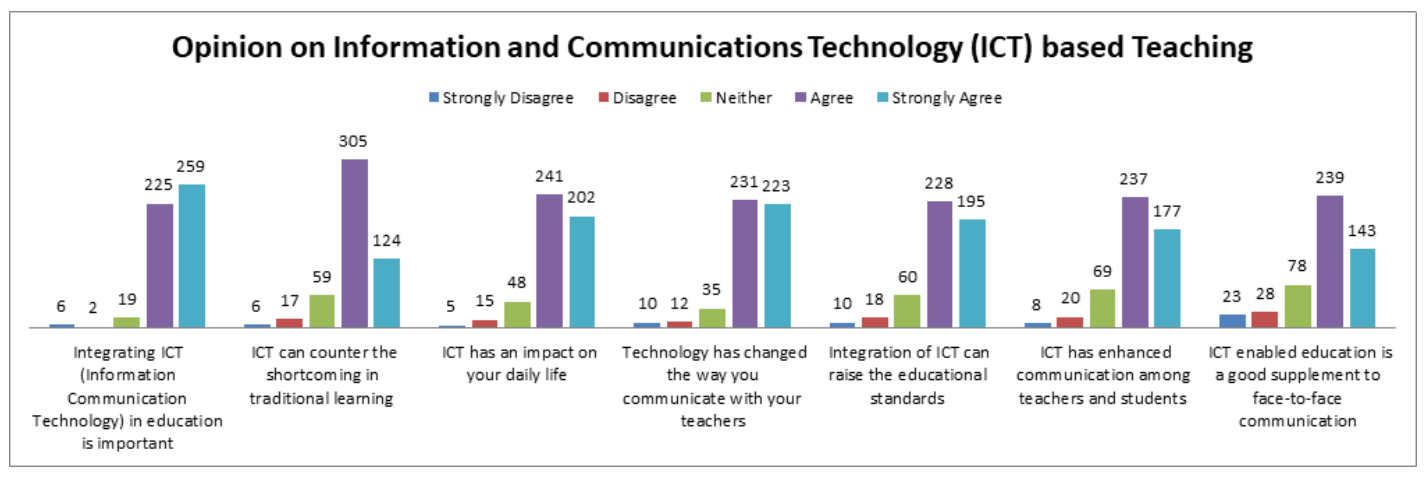

The overall analysis shows that the students favor using ICT for learning. It has helped to keep their interest in education alive in the pandemic times.

\subsection{Changes in communication behavior due to ICT using WhatsApp:}

In this category, nine statements were given to the students specifically related to communication behavior after implementing WhatsApp as ICT.

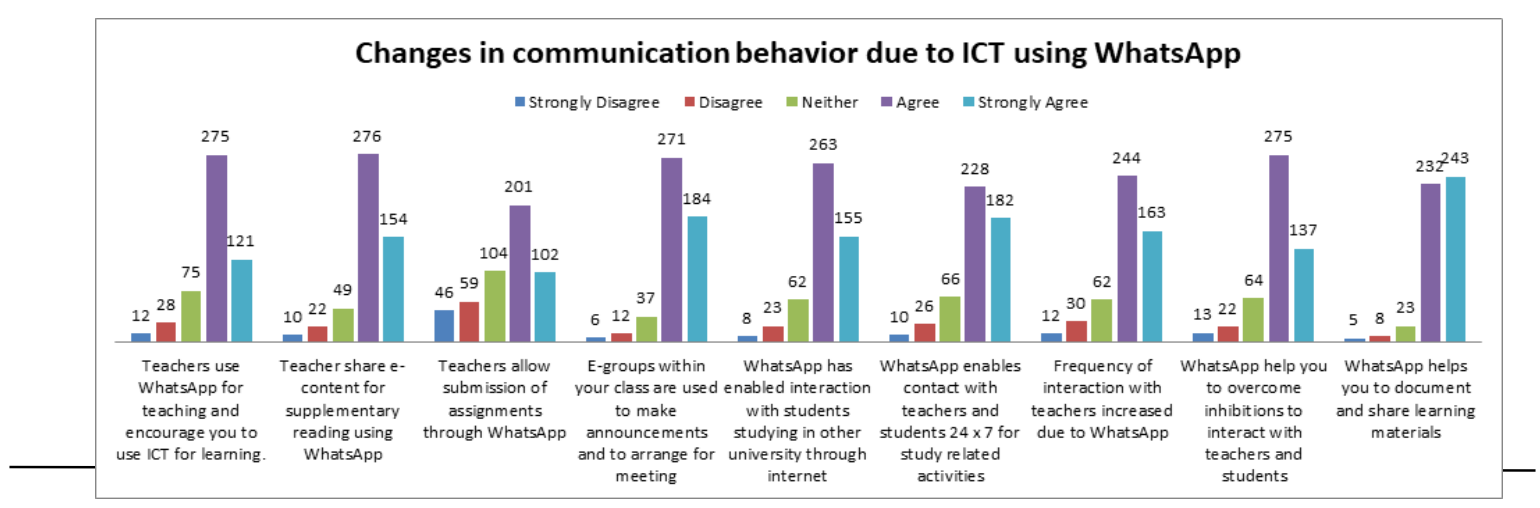


From the graphs, it is seen that the majority of the teachers have used WhatsApp effectively and also encouraged the students to use ICT for learning. Teachers have allowed submission of assignments through WhatsApp. WhatsApp helped students to document and share learning materials whereby teachers shared e-content for supplementary reading using the same app. It was observed that, in the pandemic times, most of the teachers have created their own WhatsApp group for each class, which was used to make announcements and to arrange for meetings. Students have also managed to use WhatsApp for interacting with students studying in other universities, besides being connected with their classmates and teachers 24 x 7 for study related activities. WhatsApp has helped students to overcome inhibitions to interact with teachers and students, creating an increase in the frequency of interaction with teachers.

The overall analysis shows that the students using ICT has reduced the communication gap between students and teachers and also among the students of different universities. The effectiveness of exchange of education-related data has improved the overall teachinglearning experience with the help of WhatsApp.

\subsection{Hindrance for integration of ICT in the teaching-learning process}

Under this criterion, eight statements related to the factors responsible for hindrance of integration of ICT in the teaching-learning process were presented to the students. Based on the responses of students it was seen that the biggest hindrance for using ICT is the internet connectivity issues.

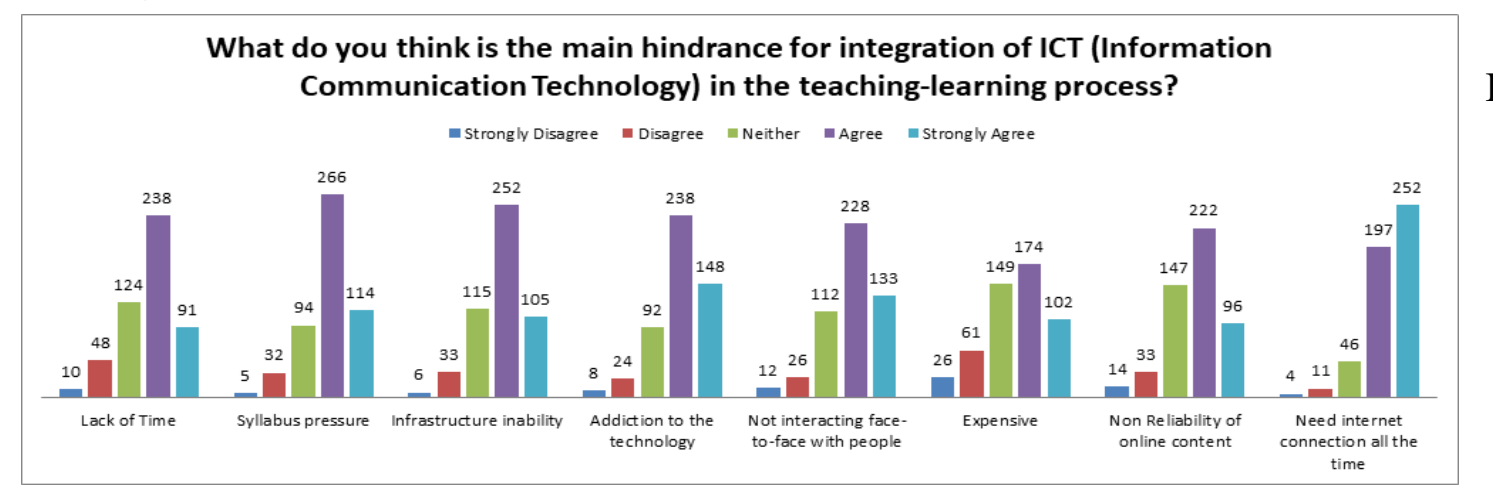

addition, students have also shown concern for chances of getting addicted to technology as a significant hindrance. Many of the students have said that, too much ICT is replacing face-toface communication with peers, and the group discussion on online platform is not effective as compare to the office interaction. Other contributing factors that students face are cost, lack of time, syllabus pressure and infrastructure inability. Along with this, students have also shown awareness about non reliability of online content which may affect their learning.

The overall analysis shows that the students are aware of the several issues that are causing hindrance to the integration of ICT in the teaching-learning process with the biggest issue of internet connectivity at all times. 


\subsection{Disadvantages of using ICT for teaching and learning}

To understand the negative impact of ICT in teaching-learning process, six statements related to the behavior of the students were asked for analysing how they react to the statements.

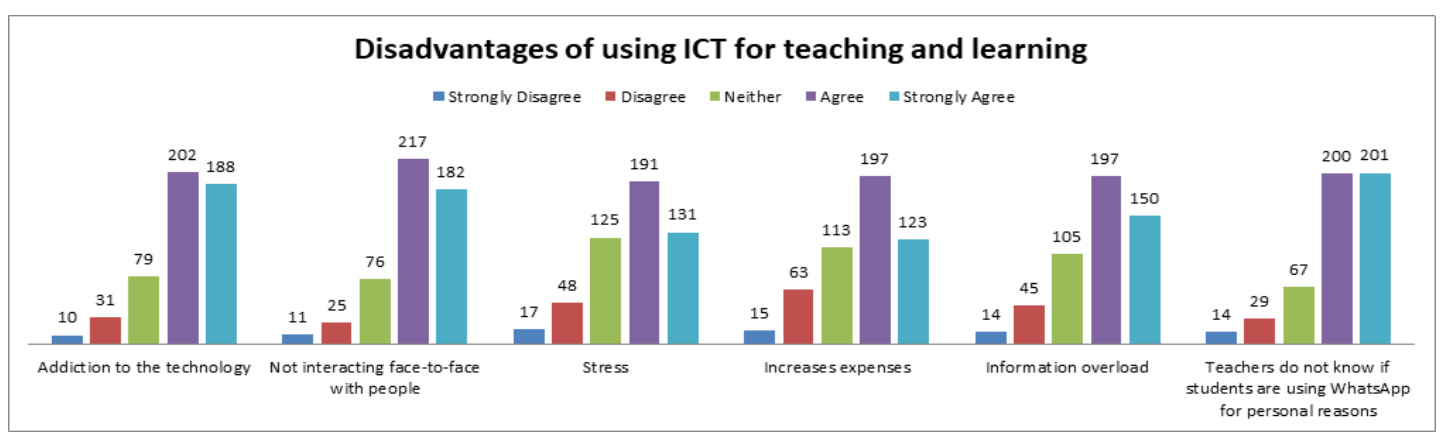

According to the data, the biggest disadvantage of using ICT for teaching-learning is that teachers will not be able to judge whether the students are using the technology for education related matters only while they are attending online lectures. Students have shown concern on the possibility of getting addicted to the technology, stress arising out of it, information overload and the additional expenses. Students are also concerned about lack of interpersonal (face-to-face) communication, which could affect their mental health too.

The overall analysis shows that the students are aware of the several disadvantages of using ICT in the teaching-learning process with the biggest disadvantage being misuse of the technology by students for their personal use apart from educational reasons.

The primary data collected from the respondents was qualitative data. It was collected with the help of a multiple-choice grid having several statements grouped into four categories and each of the statement had a choice of 5 responses namely: Strongly agree, Agree, Neutral, Disagree and Strongly disagree. In order to perform regression analysis on this data it was necessary to quantify the data. Hence, it was converted into numeric value as follows: 1 (Strongly agree), 2 (Agree), 3 (Neutral), 4 (Disagree), and, 5 (Strongly disagree). The data was collected from 30 statements which were divided into 4 groups, and then the average was taken group-wise to reduce 30 variables to 4 variables (V1, V2, V3 and V4) for regression analysis. The result of the regression analysis shows that WhatsApp can be used as an ICT tool in Higher Education System with the significance value of 0.0152 using ANOVA test.

\section{CONCLUSION}

To measure the impact of WhatsApp as an Information and Communications Technology (ICT) tool in Higher Education System, the researchers used ANOVA regression test which resulted in significance value of 0.0152 . With this, it can be concluded that, WhatsApp can be used as an ICT tool for educational purpose ignoring the disadvantages.

From the above analysis, it can be seen that students are happy to use WhatsApp for ICTbased learning. The researchers conclude that students would like to have a proper blend of ICT in daily classroom teaching to enhance the overall teaching-learning experience in the 
post pandemic era. WhatsApp has brought in tremendous changes in the communication behavior of students as well as the teachers. It is a boon for official communications such as submission of examination papers and assignments during the pandemic times.

Using WhatsApp group facility, students remain connected with their class and the faculty $24 \times 7$ which motivates them to study and learn. The biggest issues however are lack of personal communication, and dependence on internet connectivity at all times which increases mental stress. It is also learnt through students' responses that, they can get addicted to the technology and sometimes they are overloaded with information. It is also studied that, the teachers being at remote places cannot judge or have control if the students are using the technology for personal chats rather than classroom related activities and discussions during the lecture hours.

Despite of these side effects of using the application, it has been the best option for the teachers and students to interact with each other along with other tools. It is considered as the best way to submit assignment to the teachers, and on the other hand, it has become easy for teachers to track the submissions on WhatsApp instead of opening and downloading the emails from students. Based on this study, the overall conclusion is that, WhatsApp is an effective tool for ICT in Higher Education but it must be used wisely and cautiously by both the teachers and the students.

\section{REFERENCES}

1. Vasudevan, V., Gnanasekaran, A., Sankar, V., Vasudevan, S. A., \& Zou, J. (2020). Variation in COVID-19 Data Reporting Across India: 6 Months into the Pandemic. Journal of the Indian Institute of Science, 1-8.

2. Wiederhold, Brenda K. "Connecting through technology during the coronavirus disease 2019 pandemic: Avoiding "Zoom Fatigue"." (2020): 437-438.

3. Tandale, M.S. (2018). Use of WhatsApp as tool for information dissemination in the colleges of western region of Mumbai: A study. International Journal of Information Dissemination and Technology, 8(3), 147-149.

4. Barhoumi, C., " The Effectiveness of WhatsApp Mobile Learning Activities Guided by Activity Theory on Students' Knowledge Management ", Contemporary Educational Technology, 2015, 6(3), 221-238 


\section{BIOGRAPHY OF AUTHORS}

Nisha Sawant,
MCA, SET (Pune University) in Computer Science and
Applications
MBA-Finance, UGC NET in Management
Pursuing Ph.d in Data Science from OPJS University, Rajasthan
Assistant Professor, Department of Computer Applications and
Information Technology
SPES's Goa Multi-Faculty College, Dharbandora Goa

